\title{
Simulated temperature evolution of large BTES - case study from Finland
}

\section{Kimmo Korhonen Teppo Arola}

Nina Leppäharju

Petri Hakala

\begin{abstract}
The largest borehole thermal energy storage system in Finland (also one of the largest systems in Europe) is located in Sipoo, Southern Finland. The system produces heating and cooling energy for a large logistics centre and consists of 157 vertical borehole heat exchangers that are grouped into 10 blocks. The temperature of the heat carrier fluid circulated in each block has been monitored since the operation was started. A numerical model of the system was created using the finite element software COMSOL Multiphysics ${ }^{\circledR}$ in order to simulate the temperature evolution of the system and the surrounding rock mass using the monitoring data as input. Simulation results indicate that the temperature within the rock mass embodying the system has decreased as the system is imbalanced but the decrease is moderate. The temperature disturbance created by the system was found to extend 50 metres from the borehole field. Based on the simulation the shallow geothermal reservoir will suffice for the designed lifetime of the system.
\end{abstract}

\section{INTRODUCTION}

In recent years Finland has been undergoing a similar increase in the number of large-scale ground-source heat pump (GSHP) systems and borehole thermal energy storage (BTES) systems as the neighbouring Sweden and Europe in general (e.g. Gehlin, et al. 2015; The European Heat Pump Association 2015). There is no national database storing information about the number of installed borehole heat exchangers (BHEs) in Finland but the statistics of The Finnish Heat Pump Association (2018) indicate growing sales numbers of large-scale GSHPs.

Designing a large-scale BTES or GSHP system requires detailed background information about the site and the desired energy loads. In these kinds of systems, the investments are likely to be massive so a good reliability of the system and significant annual savings on energy costs are naturally expected. In the design phase, the dimensioning of the BHE field is made based on the information available at that time. However, in many cases changes occur, for example, in energy loads during the utilization of a system. One may prepare for these changes by making the system versatile and adjustable and also by adding monitoring tools to the system. Monitoring of GSHP system operation can also play an important role in identifying and resolving problems at an early stage as stated by Sanner, et al. (2016). Taking these considerations into account, the reliability of large-scale BTES systems can be increased and thus these systems can be made more appealing to investors.

Monitoring data from GSHP systems in operation have been used for system performance analysis (e.g. Luo, et al. 2015) and for the assessment of design models (e.g. Naicker and Rees 2011; Cullin, et al. 2015). Data from a welldesigned monitoring system also enables simulating the temperature response of the BHE field as well as forecasting the adequacy of the system in the upcoming years of operation. For example, Derouet, et al. (2015) used a method based on the finite line source theory to forecast the temperature decrease in a BHE field and to calculate the decrease in seasonal performance factor (SPF) in the upcoming 20 years. Lanini, et al. (2014) and Rapantova, et al. (2016) both used experimental data to calibrate a numerical BTES model. They used the models to optimize BTES operation and to formulate guidelines for BTES design. Tordrup, et al. (2016) used a numerical model validated with monitoring data to upscale a pilot-size BTES to full scale.

Kimmo Korhonen and Nina Leppäharju are Geophysicists, Petri Hakala is a Research Scientist and Teppo Arola is a Chief Expert at the Engineering Geology and Geoenergy Unit of the Geological Survey of Finland. E-mail addresses are in form firstname.lastname@gtk.fi. 
Recently, new tools have been introduced for GSHP performance monitoring. Monzo, et al. (2016; 2017) presented a large-scale BTES installation with a carefully designed monitoring system and the first measurements from data collection sensors and distributed temperature sensing (DTS) optical fibre cables. DTS offers detailed information of the vertical variations of the thermal response of the ground. In large BHE fields, differences may also exist between the thermal performances of different parts of the field, for example, between the inner and outer BHEs, or due to varying geological properties of the site.

In this paper we present long-term monitoring data and simulated temperature response of one of the largest BTES systems in Europe. The BTES has been in operation since 2012 and the performance of the system has been monitored since the beginning. A numerical model was developed to simulate the temperature response of the BHE field and to evaluate the thermal performance of the system. This BTES system and the monitoring data starting from 2012 will be studied in more detail in further work. This kind of long-term monitoring of BTES operation is called for in order to further improve designing of large-scale systems and enable commercial development.

\section{THE BOREHOLE THERMAL ENERGY STORAGE}

\section{Description of the BTES}

The BTES system provides heating and cooling energy for a large logistics centre located in Sipoo, Southern Finland. The system has been in operation since 2012. The BTES is operated jointly with a pellet fuel bioenergy system forming a hybrid energy system. The heat pumps provide approximately 5,100 MWh of space heating energy and 1,200 MWh of cooling energy annually (according to the average values from 2012-2017). The SPF of the system in heating mode has been around 3.5 on average over the years based on the amount of heating energy produced and electrical energy input.

The BTES system consists of an array of vertical groundwater filled BHEs, which are installed nearly symmetrically on a rectangular grid (Figure 1). Most of the BHEs are located under the logistics centre building. The extent of the BHE field is $310 \mathrm{~m}$ by $270 \mathrm{~m}$ and the average distance between the boreholes is $25 \mathrm{~m}$. The total number of BHEs is 157 and the average active depth is $280 \mathrm{~m}$ (ranging from $68 \mathrm{~m}$ to $303 \mathrm{~m}$ with a mode of $300 \mathrm{~m}$ ). In 7 cases the nominal depth of 300 metres could not be reached while drilling and a secondary borehole was drilled close to the first one and the two boreholes were connected in series. The BHEs are grouped into 10 blocks (i.e. into 10 manifolds). The borehole diameter is $140 \mathrm{~mm}$. The collectors are single $\mathrm{U}$ pipes (40 mm diameter) in 9 blocks and TurboCollector ${ }^{\circledR}$ pipes $(40 \mathrm{~mm}$ diameter) in one block. All the BHEs were installed with collector spacers having a shank spacing of $75 \mathrm{~mm}$.

In winter time in heating mode all the blocks are normally in use. In summer time each block can be recharged using energy from space cooling. In addition, solar energy is collected using horizontal heat exchanger pipes installed under part of the tarmac covering the loading bay for trucks. The collected solar energy can be fed to selected BHE blocks for recharging.

The geology of the site was mapped in detail in 2008 before the BTES was designed. Field observations and analyses of drill cuttings (from test boreholes) suggested 2 different sorts of igneous rock types, diorite and granitic gneiss, with a relatively ragged boundary (Figure 1).

\section{Monitoring of the BTES}

The performance of the BTES system has been monitored since the beginning of the operation in 2012. The temperature of the heat carrier fluid entering and exiting each block is measured with Ni1000 temperature sensors. The volumetric flow rates were measured for each BHE using an ultrasonic flow meter. The flow rates are not monitored continually. Instead, the flow rates are considered constant over time since the circulation pumps have been operating on non-stop since 2012.

The monitoring system also includes DTS measurements using optic fibre cables in selected BHEs and 
additional monitoring boreholes interior to the BHE field. In total, 15 kilometres of optic cable has been installed into the BTES system. However, the DTS data will not be addressed in this paper but will be a subject for future studies.

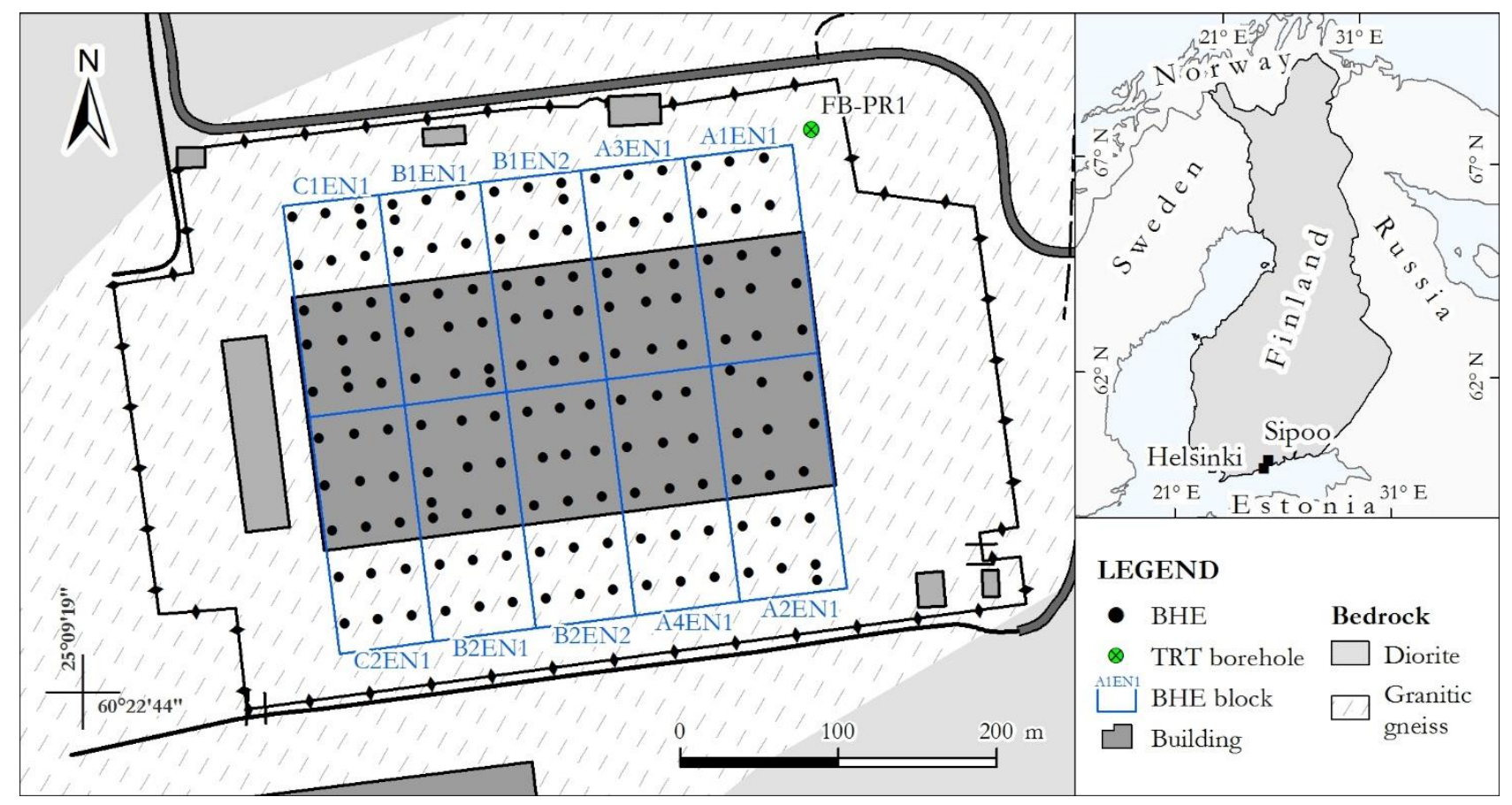

Figure 1. Plan view of the borehole thermal energy storage system located in Sipoo, Southern Finland. The extent of the borehole heat exchanger (BHE) field is $310 \mathrm{~m} \mathrm{x} 270 \mathrm{~m}$. It consists of 157 vertical BHEs, most of which are located under a logistics centre building. The BHEs are grouped into 10 blocks. For reference, the area of each block is approximately that of a standard football field. The BHE field is situated in granitic gneiss bedrock.

\section{NUMERICAL BTES MODEL}

A numerical model of the BTES was constructed using the finite element modelling software COMSOL Multiphysics ${ }^{\circledR}$ (version 5.3). The purpose of the model was to simulate the operation of the BTES in order to determine its temperature evolution and the extent of the temperature disturbance created by it.

\section{Geometry and mesh}

Modelling such a large BTES requires a large number of elements. In order to keep the number of elements at a manageable level for a desktop computer, three simplifications were made. The first simplification was to assume that all the boreholes were completely vertical and to round the lengths of the boreholes to the nearest 25 metres. This reduced the number of different borehole lengths from 42 to 8 (Figure 2a).

The second simplification was to solve the equations describing heat transfer inside the BHEs in two dimensions on the boundaries representing the walls of the boreholes. This allowed to exclude the detailed three dimensional internal structure of the BHEs from the model geometry and meshing which reduced the complexity of the model significantly. The boreholes were represented by cylinders which were carved out of the volume representing the bedrock using constructive solid geometry operations (Figure 2b).

The third simplification was to use sweep meshing (Figure $2 \mathrm{~b}$ ). The edges comprising the collars of the boreholes were first meshed with edge elements having the maximum length of $25 \mathrm{~mm}$. Then the ground surface boundary was meshed using triangular elements. Finally, the mesh at the ground surface was swept down to the bottom of the model at intervals having the maximum length of 25 metres. The final mesh consisted of 1,397,126 
elements, of which, 1,354,494 were prismatic (97\%).
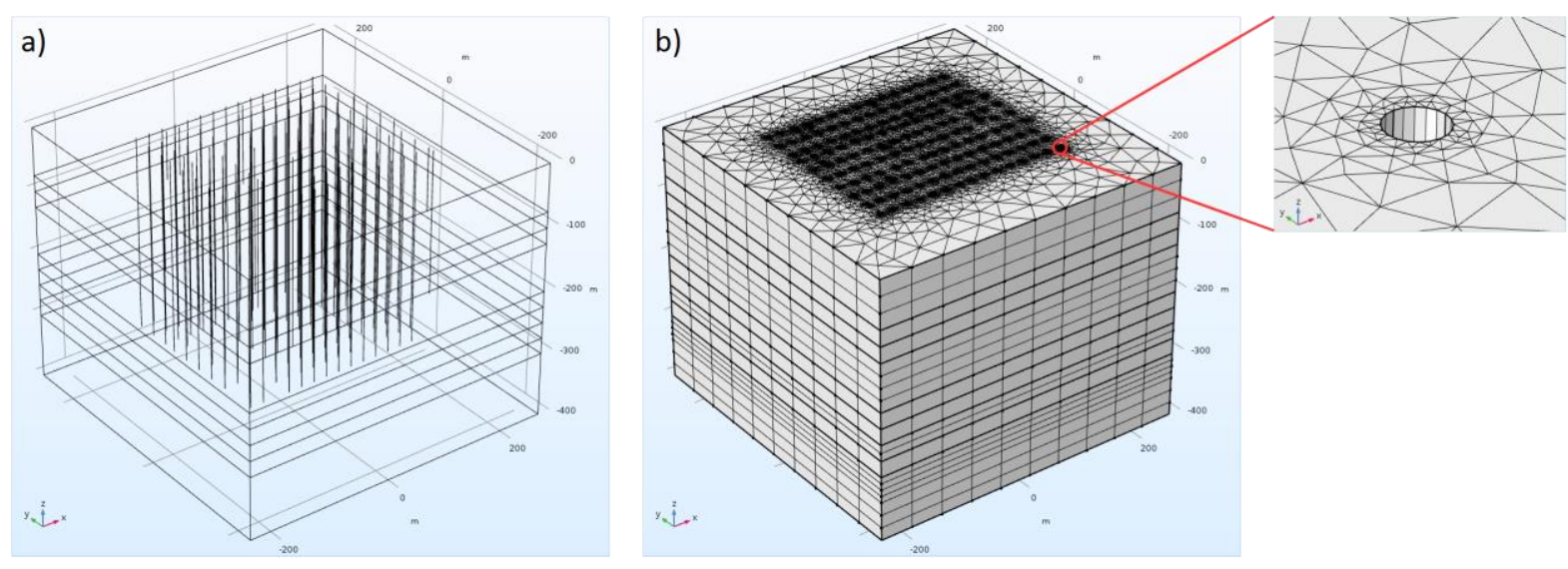

Figure 2. Geometry and meshing of the borehole thermal energy storage model. a) The model consists of 157 boreholes of 8 different lengths that are carved out of the three-dimensional volume representing the bedrock. b) The final three-dimensional mesh was generated by sweeping the two-dimensional ground surface mesh down to the bottom of the model.

\section{Governing equations}

The heat transfer inside a BHE can be described accurately enough using three coupled partial differential equations without resorting to the use of three dimensional elements. The equations describe the heat transfer in the downflow shank, in the upflow shank, in the grouting, and between the pipes and grouting. This solution was presented, for example, in Saeid, et al. (2013), Diersch, et al. (2011) and Al-Khoury, et al. (2010). However, they solved the equations in one dimensional line elements while we solved them in two dimensional quadrilateral boundary elements representing the borehole walls.

Heat transfer in the downflow shank (denoted by the subscript d) was described using the equation

$$
\rho_{\mathrm{f}} C_{\mathrm{f}} \frac{\partial T_{\mathrm{d}}}{\partial t} \mathrm{~d} V_{\mathrm{p}}-k_{\mathrm{f}} \nabla^{2} T_{\mathrm{d}} \mathrm{d} V_{\mathrm{p}}-\rho_{\mathrm{f}} C_{\mathrm{f}} u \frac{\partial T_{\mathrm{d}}}{\partial z} \mathrm{~d} V_{\mathrm{p}}=b_{\mathrm{fg}}\left(T_{\mathrm{g}}-T_{\mathrm{d}}\right) \mathrm{d} S_{\mathrm{p}}
$$

in the upflow shank (denoted by the subscript $\mathrm{u}$ ) using the equation

$$
\rho_{\mathrm{f}} C_{\mathrm{f}} \frac{\partial T_{\mathrm{u}}}{\partial t} \mathrm{~d} V_{\mathrm{p}}-k_{\mathrm{f}} \nabla^{2} T_{\mathrm{u}} \mathrm{d} V_{\mathrm{p}}+\rho_{\mathrm{f}} C_{\mathrm{f}} u \frac{\partial T_{\mathrm{u}}}{\partial z} \mathrm{~d} V_{\mathrm{p}}=b_{\mathrm{fg}}\left(T_{\mathrm{g}}-T_{\mathrm{u}}\right) \mathrm{d} S_{\mathrm{p}}
$$

and in the grouting (denoted by the subscript g) using the equation

$$
\rho_{\mathrm{g}} C_{\mathrm{g}} \frac{\partial T_{\mathrm{g}}}{\partial t} \mathrm{~d} V_{\mathrm{g}}-k_{\mathrm{g}} \nabla^{2} T_{\mathrm{g}} \mathrm{d} V_{\mathrm{g}}=b_{\mathrm{fg}}\left(T_{\mathrm{d}}-T_{\mathrm{g}}\right) \mathrm{d} S_{\mathrm{p}}+b_{\mathrm{fg}}\left(T_{\mathrm{u}}-T_{\mathrm{g}}\right) \mathrm{d} S_{\mathrm{p}}+b_{\mathrm{gr}}\left(T_{\mathrm{r}}-T_{\mathrm{g}}\right) \mathrm{d} S_{\mathrm{g}}
$$

In these equations the subscript $\mathrm{f}$ refers to heat carrier fluid, $\mathrm{g}$ refers to grouting, and $\mathrm{r}$ refers to bedrock. Density is $\rho$, $C$ is specific heat capacity (in constant pressure), $k$ is thermal conductivity, $T$ is temperature and $t$ is time. Heat transfer between the heat carrier fluid and the grouting is characterized by the heat transfer coefficient $b_{\mathrm{fg}}$ and between the grouting and the surrounding bedrock by the heat transfer coefficient $b_{\mathrm{gr}}$. Furthermore, the volume element $\mathrm{d} V_{\mathrm{p}}$ represents the volume of a pipe element of height $\mathrm{d} z, \mathrm{~d} S_{\mathrm{i}}$ represents the surface area of the same pipe element, $\mathrm{d} V_{\mathrm{g}}$ represents the volume of a grouting element of height $\mathrm{d} z$, and $\mathrm{d} S_{\mathrm{g}}$ represents the surface area of the grouting element at the borehole wall. The equation governing heat transfer in the bedrock domain was 


$$
\rho_{\mathrm{r}} C_{\mathrm{r}} \frac{\partial T_{\mathrm{r}}}{\partial t}+\nabla \cdot\left(-k_{\mathrm{r}} \nabla T_{\mathrm{r}}\right)=b_{\mathrm{gr}}\left(T_{\mathrm{g}}-T_{\mathrm{r}}\right)
$$

which was solved in three dimensions.

Equations (1)-(3) solve the flow of heat between the heat carrier fluid and the grout on two-dimensional boundary elements. The magnitude of heat flow between the pipes and the grout is determined based on the heat transfer coefficient $b_{\mathrm{fg}}$. The grout acts as mediator of heat between the heat carrier fluid and the bedrock. Equations (3) and (4) (two-dimensional and three-dimensional elements) are coupled to each other through the heat transfer coefficient $b_{\mathrm{gr}}$ which determines the magnitude of heat flow between the grout and the bedrock.

\section{Model parameters}

The thermal properties of the heat carrier fluid were estimated using the polynomial interpolation equation of Melinder (2007). The thermal conductivity, specific heat capacity and density of a water-alcohol mixture with 28 weight $\%$ ethanol at $15{ }^{\circ} \mathrm{C}$ with were estimated to be $0.418 \mathrm{~W} / \mathrm{m} \cdot \mathrm{K}, 4239 \mathrm{~J} / \mathrm{kg} \cdot \mathrm{K}$ and $960.1 \mathrm{~kg} / \mathrm{m}^{3}$ respectively. As the boreholes are groundwater-filled, the density and specific heat capacity of the grouting were estimated to be 999 $\mathrm{kg} / \mathrm{m}^{3}$ and $4185 \mathrm{~J} / \mathrm{kg} \cdot \mathrm{K}$ respectively, based on Incropera, et al. (1990). To account for natural convection occurring in the borehole water, the thermal conductivity of the groundwater filling was set to the value of $1.8 \mathrm{~W} / \mathrm{m} \cdot \mathrm{K}$ ( 3 times that of stagnant water). The density and specific heat capacity of the bedrock were set to the values of $2700 \mathrm{~kg} / \mathrm{m}^{3}$ and $890 \mathrm{~J} / \mathrm{kg} \cdot \mathrm{K}$ respectively.

The heat transfer coefficients together with the bedrock thermal conductivity were estimated by fitting the model to TRT data (refer to Figure 1 for the location of the borehole in which the test was carried out). The heat transfer coefficients $b_{\mathrm{gg}}$ and $b_{\mathrm{gr}}$ were estimated to be $149.658 \mathrm{~W} / \mathrm{m}^{2} \cdot \mathrm{K}$ and $39.800 \mathrm{~W} / \mathrm{m}^{2} \cdot \mathrm{K}$ respectively, and the bedrock thermal conductivity was estimated to be $3.6 \mathrm{~W} / \mathrm{m} \cdot \mathrm{K}$.

\section{Initial values and boundary conditions}

The ground temperature distribution was measured in 2010 in one of the boreholes comprising the BTES using DTS. The measurements were carried out before the construction work of the logistics centre was begun, thus, giving the undisturbed ground temperature profile. The measured profile was smoothed and used as the initial temperature in the model.

The constant temperature boundary condition was applied to the ground surface boundary. The temperature at the ground surface was chosen to be $6.698{ }^{\circ} \mathrm{C}$ which was the measured initial temperature at the ground surface. The flux boundary condition was applied to the bottom boundary of the model. The flux was set equal to the geothermal heat flux of $43.912 \mathrm{~mW} / \mathrm{m}^{2}$ which was solved from the measured ground temperature profile assuming the thermal conductivity of the bedrock to be $3.6 \mathrm{~W} / \mathrm{m} \cdot \mathrm{K}$. The no-flux boundary condition was applied to all the vertical boundaries of the model which were taken far enough from the BTES so as not to be affected by the temperature disturbance created by it.

\section{RESULTS}

Simulation of the BTES operation was carried out by feeding the observed inlet temperature of a block to the inlets of each of the BHEs comprising that block. The BHEs in a block were connected in parallel except in seven cases in which two BHEs were connected in series. In these cases, the calculated outlet temperature of the first BHE was fed as the inlet temperature to the second BHE. The simulated outlet temperatures for each block were calculated as the average temperature of all the BHE outlet temperatures in that block.

The simulation time step was chosen to be 1 day to make the computational time reasonable ( 8 hours). The length of the simulation time period was 1937 days (5.3 years). The temperature records for each block were logged typically at the time intervals of 10, 20 and 60 minutes. However, the logging interval changes irregularly in each temperature record and may be even as small as few seconds or as large as one day. Thus, the irregular temperature 
records needed to be made uniform using averaging. Moreover, smoothing using a 10-day moving window was used to average out the highly variable records in order to avoid numerical instabilities which would have otherwise arisen due to large time step and element size. The time step and mesh size were chosen based on a convergence analysis. Finer space and time discretization would have only a minimal effect on the result.

Figure 3 shows the observed inlet and outlet fluid temperatures together with the simulated outlet temperatures and the differences between the observed and simulated outlet temperatures (residuals) for each borehole block. The difference between the observed and simulated temperatures is virtually zero in blocks B1EN2 and B2EN2. In other blocks the simulated outlet temperatures trace the observed temperatures with a margin of few tenths of kelvins. However, in blocks A2EN1 and B2EN2 the misfit during the first year of the simulation is significantly larger (the residuals reach even $1.5 \mathrm{~K}$ ). Similarly, in block B1EN1 the misfit is significantly larger but during the second year of simulation.
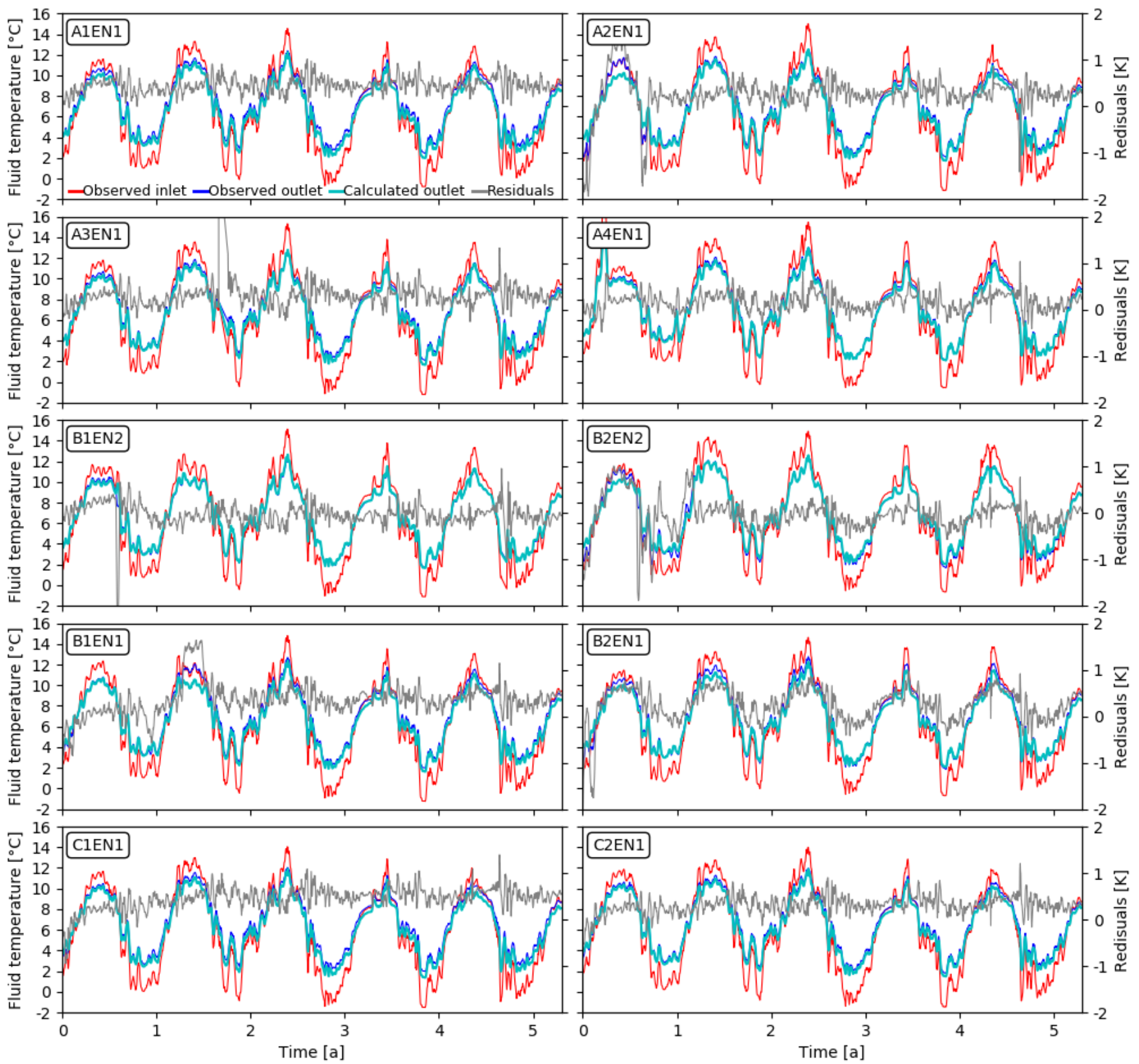
Figure 3. Observed and simulated temperatures, and residuals (the difference between observed and simulated outlet temperature) for each borehole heat exchanger block.

Table 1 lists the observed and simulated total energy amounts utilized each year and the relative error. The total energy amounts were calculated as the sums of injected and extracted energy for each year. The years 2012 and 2017 are not fully covered by data (they lack 3 and 6 months of data respectively). There is a large relative error in the simulated energy amount for the year 2012 but otherwise the relative errors are not larger than $5 \%$.

Table 1. Total energy loads extracted from the BTES.

\begin{tabular}{cccc}
\hline Year & Observed load [MWh] & Simulated load [MWh] & Relative error [\%] \\
\hline \hline 2012 & 2649 & 3191 & 20.5 \\
2013 & 4686 & 4755 & 1.5 \\
2014 & 4519 & 4391 & 2.8 \\
2015 & 4212 & 4119 & 2.2 \\
2016 & 4730 & 4798 & 1.4 \\
2017 & 2360 & 2243 & 5.0 \\
\hline
\end{tabular}

Figure 4 shows the horizontal and vertical temperature disturbances created by the BTES on horizontal and vertical planes cutting through it. The disturbance was calculated by first averaging the temperature over the last year of the simulation and then subtracting the undisturbed temperature from the calculated average. The extent of the horizontal and vertical temperature disturbances appear to be 50 metres judging by the $-1 \mathrm{mK}$ isotherms (which was considered as negligible disturbance) shown in Figure 4.
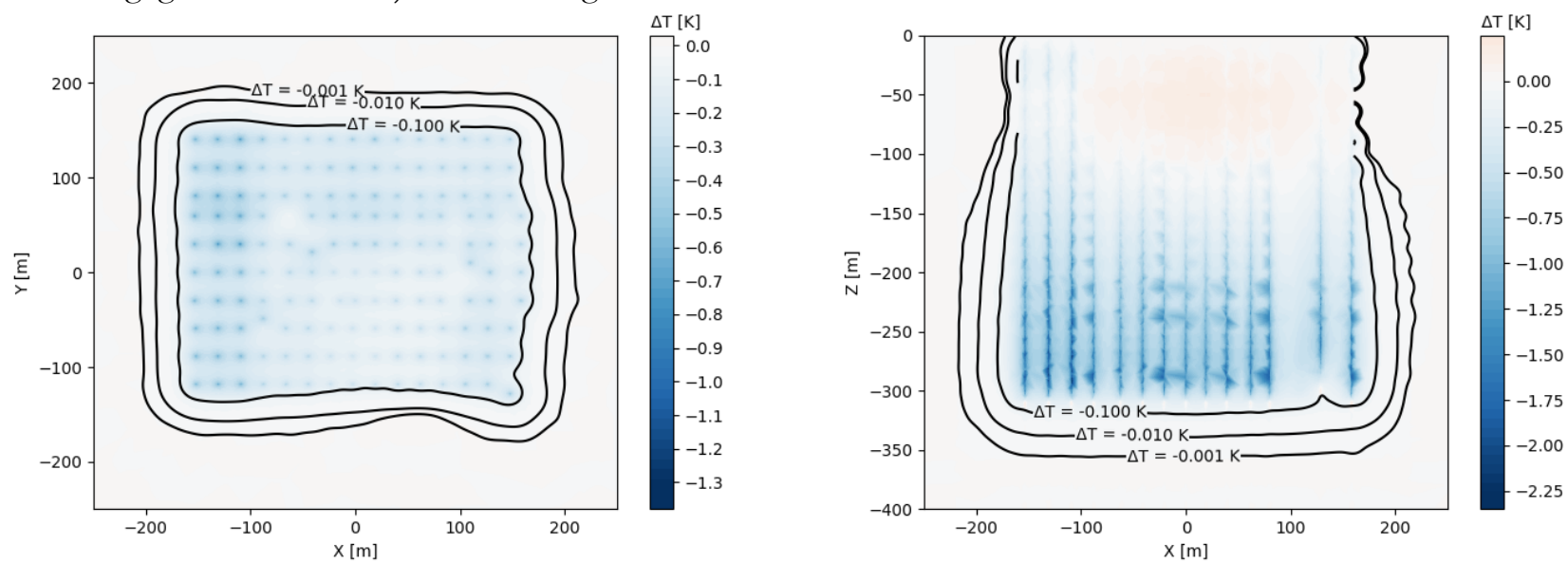

Figure 4. Spatial extent of the simulated temperature disturbance created by the BTES. The left panel shows the horizontal extent on the XY plane at the depth of 150 metres. The right panel shows the vertical extent on the XZ plane throught the center of the BTES.

\section{DISCUSSION AND CONCLUSIONS}

The simulated outlet temperatures agree quite well with the observed outlet temperatures as is shown by Figure 3. In some cases the fit is not excellent (the residuals reach $0.5 \mathrm{~K}$ ) but for the objective of this study the accuracy is considered sufficient. In the case of blocks A2EN1, B1EN1 and B2EN2 the simulated outlet temperatures do not appear to fit the observed temperatures well during specific periods of time (the first or second year of the simulation). This is most likely due to errors in the outlet temperature sensors as the temperature difference between the inlet and outlet is virtually or close to zero during those periods even though the blocks have been in full use. Inaccuracies in the monitoring data were detected already before this study and improvements are planned in order to increase the usability of the monitoring data. The simulation results further highlight the need for improvements. 
However, for this study the quality of the data was considered to be sufficient.

The observed and simulated total energy amounts extracted from the BTES also appear to agree well as is shown by Table 1 . The large relative error of 2012 is likely due to the identified sensor problems as well as adjustments made in the operation of the system (for example in fluid flow rates).

The temperature disturbance created by the BTES has not advanced far even though the BHE field is large and the amount of thermal energy extracted from the system has been larger than the amount of injected thermal energy. The advancing negative temperature disturbance illustrated by the isotherms in Figure 4 is due to this unbalance in the energy loads. There is also a slight downwards trend in the observed inlet and outlet temperatures seen in Figure 3 which could be removed if the BTES was recharged more. The unbalance in the loads was, however, acknowledged and taken into account in the design phase of the system. Within the first 5 years of operation the temperature decrease appears to be about $2 \mathrm{~K}$. The BTES was designed for a 25-year lifetime and as the steepest decrease in temperatures is expected during the first years of operation the results indicate that with these load levels the heat reservoir will not be depleted. However, balancing the energy loads would improve the performance of the system.

As a next step, we aim to improve the fit between the observed and simulated temperatures. To achieve this, we will fit each block individual model parameters and carry out simulations using a finer mesh and a smaller time step. As the BTES is equipped with a DTS monitoring system, the DTS data will also be used in order to further validate the model and investigate the temperature evolution of the BTES in more detail. In future we also intend to investigate the thermal performance of each BHE block individually.

\section{ACKNOWLEDGMENTS}

We thank S Group and Adven for their support regarding our reseach and for the permission to use the monitoring data. We also thank our colleagues Ilkka Martinkauppi and Isa Witick whose help was vital for the completion of this paper.

\section{NOMENCLATURE}

$$
\begin{aligned}
\rho & =\text { density }\left(\mathrm{kg} / \mathrm{m}^{3}\right) \\
C & =\text { specific heat capacity }(\mathrm{J} / \mathrm{kg} \cdot \mathrm{K}) \\
k & =\text { thermal conductivity }(\mathrm{W} / \mathrm{m} \cdot \mathrm{K}) \\
T & =\text { temperature }(\mathrm{K})
\end{aligned}
$$

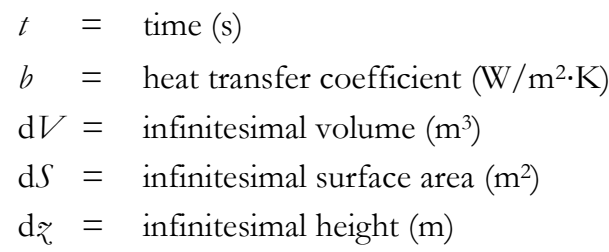

\section{Subscripts}

$\mathrm{d}=$ downflow shank of a $\mathrm{U}$ pipe

$\mathrm{u}=$ upflow shank of a $\mathrm{U}$ pipe

$\mathrm{g}=$ grouting of a borehole heat exchanger

$$
\begin{aligned}
& \mathrm{f}=\text { heat carrier fluid } \\
& \mathrm{r}=\text { bedrock }
\end{aligned}
$$

\section{REFERENCES}

Al-Khoury, R., Kolbel, T. and Schramedei, R. 2010. Efficient numerical modeling of borehole heat exchangers. Computers \& Geosciences, 36, pp. 1301-1315.

Cullin, J.R., Spitler, J.D., Montagud, C., Ruiz-Calvo, F., Rees, S.J., Naicker, S.S., Konečný, P. and Southard, L.E. 2015. Validation of vertical ground heat exchanger design methodologies. Science and Technology for the Built Environment, 21, 137149.

Derouet, M., Monzó, P. and Acuña, J. 2015. Monitoring and Forecasting the Thermal Response of an Existing Borehole Field. World Geothermal Congress 2015. Melbourne, Australia. April 19-25. Available online at: https://www.kth.se/polopoly_fs/1.571163!/published\%20paper.pdf 
Diersch, H.-J.G., Bauer, D., Heidemann, W., Ruhaak, W. and Schatzl, P. 2011. Finite element modeling of borehole beat exchanger systems. Part 1. Fundamentals. Computers \& Geosciences, 37, pp. 1122-1135.

European Heat Pump Association. 2015. European Heat Pump Market and Statistics Report 2015. Executive Summary. Available online at: http://www.ehpa.org/fileadmin/red/07._Market_Data/2014/EHPA_European_Heat_Pump_Market_and_

Statistics_Report_2015_-_executive_Summary.pdf

Gehlin, S., Andersson, O., Alm, P-G. and Rosberg, J-E. 2015. Country Update for Sweden. World Geothermal Congress 2015. Melbourne, Australia. April 19-25. Available online at: https://pangea.stanford.edu/ERE/db/WGC/papers/WGC/2015/01021.pdf

Incropera, F. P. and de Witt, D. P. 1990. Fundamentals of Heat and Mass Transfer. 3rd edition, Wiley, New York, 919 p.

Lanini, S., Delaleux, F., Py, X., Olivès, R. and Nguyen, D. 2014. Improvement of borehole thermal energy storage design based on experimental and modelling results. Energy and Buildings, 77, pp. 393-400.

Luo, J., Rohn, J., Bayer, M., Priess, A., Wilkmann, L. and Xiang, W. 2015. Heating and cooling performance analysis of a ground source heat pump system in Southern Germany. Geothermics 53, 57-66.

Melinder, A. 2007. Thermophysical Properties of Aqueous Solutions Used as Secondary Working Fluids. Doctoral thesis, Royal Institute of Technology, Stockholm, Sweden, $130 \mathrm{p}$.

Monzó, P., Lazzarotto, A., Acuña, J., Tjernström, J. and Nygren, M. 2016. Monitoring of a borehole thermal energy storage in Sweden. 12th REHVA World Congress - Clima 2016. Aalborg, Denmark. May 22-25. Available online at: http://kth.divaportal.org/smash/get/diva2:932875/FULLTEXT01.pdf

Monzó, P., Lazzarotto, A. and Acuña, J. 2017. First Measurements of a monitoring BTES system. IGSHPA Technical/Research Conference and Expo 2017. Denver, USA. March 14-16.

Naicker, S.S. and Rees, S.J. 2011. Monitoring and Performance Analysis of a Large Non-domestic Ground Source Heat Pump Installation. CIBSE Technical Symposium 2011. Leicester, UK. Sept 6-7.

Rapantova, N., Pospisil, P., Koziorek, J., Vojcinak, P., Grycz, D. and Rozehnal, Z. 2016. Optimisation of experimental operation of borehole thermal energy storage. Applied Energy, 181, pp. 464-476.

Saeid, S., Al-Khoury, R. and Barends, F. 2013. An efficient computational model for deep low-enthalpy geothermal systems. Computers \& Geosciences, 51, pp. 400-409.

Sanner, B., Bockelmann, F., Kühl, L. and Mands, E. 2016. System optimisation of ground-coupled heat and-cold supply of office buildings. European Geothermal Congress 2016. Strasbourg, France. Sept 19-24.

The Finnish Heat Pump Association. 2018. Heat Pump Investments up to Half a Billion a Year in Finland. Press release 1/2018. Available online at: https://www.sulpu.fi/documents/184029/0/Press\%20Realaese $\% 20$ $\% 20$ Heat $\% 20$ Pump $\% 20$ Investments $\% 20$ up $\% 20$ to $\% 20 \mathrm{a} \% 20$ Half $\% 20$ Billion $\% 20 \mathrm{a} \% 20$ Year $\% 20$ in $\% 20$ Finland $\% 2 \mathrm{C} \% 20$ 2.pdf

Tordrup, K.W., Poulsen, S.E. and Bjørn, H. 2016. An improved method for upscaling borehole thermal energy storage using inverse finite element modelling. Renewable Energy, 105, pp. 13-21. 